\title{
"Emailisation" of the public sector: tracing the prevalence of use of email in Zimbabwe's central government
}

\author{
Samson Mutsagondo \\ University of South Africa, South Africa \\ 57649308@mylife.unisa.ac.za \\ http://orcid.org.0000-0001-8554-1241
}

\author{
Patrick Ngulube \\ University of South Africa, South Africa \\ ngulup@unisa.ac.za \\ http://orcid.org.0000-0002-7676-3931
}

Received: 08 March 2021

Revised: 24 June 2021

Accepted: 11 August 2020

\begin{abstract}
Although paper is still the dominant records format in Zimbabwe, there has been a remarkable rise in use of electronic records, of which electronic mail (email) is a subset. Email dawned in the 1970s but it has increasingly gained much traction in official information and communication in Zimbabwe's central government in the current decade. The use of email has become a norm or rather a culture, a development which the authors of this article metaphorically coin "emailisation". This paper traces the rise in official use of email in Zimbabwe's central government in order to establish changing trends in diffusion of innovations in information and communication. Three objectives are addressed, which are tracing how often email is used in official communication, establishing types of records normally generated and sent using email, and determining the volume of email sent and received in Zimbabwe's central government per day. This mixed methods research made use of a convergent research design and involved 240 respondents and 10 interviewees. The study calls for responsible and controlled use of email to bring the technology, both official and authentic, in line with the ethos of professional records and information management.
\end{abstract}

Keywords: diffusion of innovations; email; emailisation; email management; prevalence of use of email; Zimbabwe

\section{Introduction and background to the study}

The use of electronic records is on the rise in many countries, including Zimbabwe. One of these electronic records that has come to characterise conducting of official business is the use of electronic mail (email). This article is based on the conceptual perspectives of the innovation diffusion theory and traces how often email is used in official communication, establishes the types of records normally generated and sent using email and determines the volume of email sent and received in Zimbabwe's central government in a single working day. The article envisages establishing the prevalence of use of email in order to accord to email the reverence it deserves in records management circles. Among these are proper and professional management of email, skills development and the mobilisation of adequate and modern information and communication technology (ICT) infrastructure. 
Records in Zimbabwe have been conventionally generated, used and managed in paper format (Bhebhe 2015:108; Matangira 2016:31). Nonetheless, since the adoption of electronic government (e-government) in 2011, Zimbabwe has experienced a steady rise in the use of electronic records (Mutsagondo 2017:23; Sigauke, Nengomasha \& Chabikwa 2016:21). The e-government programme made it possible for the Government of Zimbabwe to improve its ICT infrastructural base; registering more and more internet service providers; increasing the country's incoming bandwidth; establishing the Ministry of Information, Communication Technology and Cyber Security; and promulgating two ICT policies. These developments made it possible for the flourishing of electronic records, including email, which happens to be one of the most common types of electronic records.

Zimbabwe's public service is divided into three clusters. These are central government, local authorities and subsidiary bodies. This article addressed the prevalence in use of email in the central government cluster, specifically looking at head offices of the 22 government ministries. The use of email is viewed in the wider perspective of records management in Zimbabwe, where the management of records is governed by the National Archives of Zimbabwe (NAZ) Act (1986).

\section{Purpose and objectives of the study}

The paper traces the prevalence of use of email in Zimbabwe's central government in order to accord to email the reverence it deserves as an official record and medium in information and communication circles. The three objectives of the study are:

(i) To trace how often email is used in official communication in Zimbabwe's central government.

(ii) To establish types of records normally generated and sent using email in Zimbabwe's central government.

(iii) To determine the volume of email sent and received by a single officer in Zimbabwe's central government per day.

\section{Conceptual perspectives of the study}

This study made use of three conceptual perspectives derived from the innovation diffusion theory. Ngulube (2018:3) argues that a conceptual framework comprises "ingredients" or "building blocks" of a theory. This study used three conceptual perspectives, that is, complexity, compatibility and relative advantage, which are derived from the innovation diffusion theory. In line with Ngulube (2018:3), by using part of the perspectives of a theory, the approach qualifies as a "conceptual framework" rather than a "theoretical framework". The innovation diffusion theory states that new ideas and products spread through a social system using existing channels of communication (Dearing \& Cox 2018:183).

The complexity construct advances that new technology is easily accepted and adopted if it is easy to understand and use, while technology that is complex and difficult to use may take time to be adopted, if at all. The second construct, compatibility, refers to the degree to which new and incoming technology fits in with established ways of accomplishing the same goal (Scott \& McGuire 2017:120). The new technology has to be in tandem with existing values, past 
experiences and needs of potential adopters for it to be worth trying. Those that are not compatible with the reigning values may not be adopted or may be adopted very slowly. The last construct used in this study is relative advantage. This refers to a situation where people consider the benefits of new technology relative to the old in terms of cost, monetary and other resource expenses (Dibra 2015:1457).

Conceptual perspectives derived from the innovation diffusion theory were applicable in this study as they helped to predict why there was a rise in the use of email. As the three constructs have shown, issues of simplicity in use, compatibility with conventional means of doing business and relative advantages of email have all helped to make email an ICT of choice. Due to enhanced motivation in using email, it is not surprising that email was prevalently used in Zimbabwe's central government, thus rather making it a culture.

\section{Literature review}

There is a marked increase in the use of email in the corporate world. This has been revealed by scholars like Cloy (2007:3), Kupritz and Cowell (2011:55), Sejane (2004:100) and Sigauke et al. (2016:14). Cloy (2007:3) maintains that many transactions that were previously done on paper or by using paper are now done using email. Kupritz and Cowell (2011:55) claim that there is an astronomic rise in the use of email owing to advances in ICTs. Sejane (2004:100) states that even developing countries like Lesotho are increasingly relying on email in sending and receiving official information. Sigauke et al. (2016:14) state that the increase in the use of email in Zimbabwe was not restricted to central government, as email use was also commonplace in subsidiary bodies such as state universities. Chihambakwe, Wutete and Sigauke (2017:1) also opine that there was an increase in the use of email in the private sector; for example, in private commercial banks in Zimbabwe.

Statistical figures on the international scene also show that there is a marked increase in the use of email in many business organisations. The Radicarti Group (2019:1) claims that in 2015, on average, a business email user received 88 emails and sent 34 emails per day, and estimated that by 2019, the user would be sending and receiving a total of 126 emails per day. The Radicarti Group (2019:1) also revealed that in 2015, there were nearly 2.6 billion email users in the world and estimated that the figure could rise to 2.9 billion users, which roughly accounts for one-third of the world population. Table 1 shows these statistics more clearly.

Table 1: Statistics on email received and sent in the world between 2015 and 2019

\begin{tabular}{|l|l|l|l|l|l|}
\hline Statistic & $\mathbf{2 0 1 5}$ & $\mathbf{2 0 1 6}$ & $\mathbf{2 0 1 7}$ & $\mathbf{2 0 1 8}$ & $\mathbf{2 0 1 9}$ \\
\hline Average emails sent per person per day & 34 & 33 & 32 & 31 & 30 \\
\hline Average emails received per person per day & 88 & 90 & 92 & 94 & 96 \\
\hline Average number of legitimate emails received & 76 & 76 & 76 & 76 & 77 \\
\hline Average number of spam emails received & 12 & 14 & 16 & 18 & 19 \\
\hline
\end{tabular}

(Adapted from: The Radicarti Group 2019)

Email now accounts for a big chunk of organisational records. Sigauke et al. (2016:14) state that email accounts for $50 \%$ of all business records of state universities in Zimbabwe. Thus, scholars like Middaugh (2015:277) argue that email has become the reality of day-to-day 
business, while Desai, Hart and Richards (2015:167) assert that "email is a mandatory business tool for any organisation that wants to make it in the $21^{\text {st }}$ century".

\section{Research methodology}

This study adopted a mixed method research approach as it sought to answer research questions in both quantitative and qualitative ways. The population of the study was 660 officers from the central government from where a sample of 240 records officers (ROs), administration officers (AOs) and information technology officers (ITOs) were selected and completed structured questionnaires. These officers were adjudged as playing the leading roles in generating, receiving, using, maintaining, preserving and disposing of email records. The questionnaire response rate was $36.4 \%$. The rather low response rate was mainly as a result of covid-19 lockdown restrictions which made it very difficult for the researchers to access as many respondents as they had planned. Nonetheless, respondents from more than half the government ministries, that is, 12 out of 22 government ministries, participated in the study. This gave a ministerial response rate of $54.5 \%$. In addition, 10 interviewees participated in the study - seven NAZ archivists (NAZ1; NAZ2 ... NAZ7 in line with the order in which they were interviewed), an officer from the NAZ Directorate (D1), the administration director (D2) from central government and the information technology director (D3), also from central government. All 10 targeted informants were interviewed, giving an interview response rate of $100 \%$. The convergent mixed methods research design was used and this helped to compare qualitative and quantitative findings. Quantitative responses were analysed using descriptive statistics while qualitative responses were analysed thematically using the Atlas data analysis programme.

\section{Presentation of findings}

The first objective of the study was to establish how often email was used in official communication in Zimbabwe's central government. Respondents, who comprised ROs, AOs and ITOs, were asked whether or not email had become the most widely used ICT tool for sending and receiving information in Zimbabwe's central government. Their responses are shown in Table 2.

Table 2: Frequency of email $(\mathrm{N}=240)$

\begin{tabular}{|l|c|c|c|c|}
\hline Category of officer & Yes & No & I do not know & Totals \\
\hline ROs & $62(25.83 \%)$ & $8(3.33 \%)$ & $10(4.16 \%)$ & $\mathbf{8 0}(\mathbf{3 3 . 3 3 \%})$ \\
\hline AOs & $55(22.92 \%)$ & $17(7.08 \%)$ & $8(3.33 \%)$ & $\mathbf{8 0}(\mathbf{3 3 . 3 3 \%})$ \\
\hline ITOs & $60(25 \%)$ & $17(7.08 \%)$ & $3(1.25 \%)$ & $\mathbf{8 0}(\mathbf{3 3 . 3 3 \%})$ \\
\hline Totals & $\mathbf{1 7 7}(\mathbf{7 3 . 7 5 \%})$ & $\mathbf{4 2}(\mathbf{1 7 . 4 9 \%})$ & $\mathbf{2 1}(\mathbf{8 . 7 4 \%})$ & $\mathbf{2 4 0}(\mathbf{1 0 0 \%})$ \\
\hline
\end{tabular}

A total of $177(73.75 \%)$ respondents indicated that email had become the most common ICT for sending and receiving information in Zimbabwe's central government. Only $42(17.49 \%)$ disagreed and $21(8.74 \%)$ were undecided. Since a convergent mixed methods research design was used, interview responses were used to confirm or disconfirm questionnaire responses. In addition, researchers' personal observation and document reviews were used whenever and where applicable. 
Seven NAZ archivists from the Harare Records Centre were purposively roped into the study. These archivists supervise records management practices in Zimbabwe's public service, including central government, as one of their official duties. A total of five (71.4\%) archivists agreed that email had emerged as the most popular ICT tool for sending and receiving information. Only two (28.6\%) archivists disagreed. The responses of the five archivists who corroborated the views of the 177 respondents gave the following remarks:

NAZ1 - "Email is fast and cheap".

NAZ2 - "Email is cheap and can be accessed wherever there is internet connection".

NAZ4 - "Email is the in-thing. Only laggards can choose to be left behind".

NAZ6 - "Email is the most formal ICT in business as compared to other upcoming ICTs like WhatsApp, Facebook and Instagram".

NAZ7 - "Email has an audit trail which is good for records management".

The administration director (D2) from central government also supported the view that there was extensive use of email in government ministries in Zimbabwe. She stated that technology was fast evolving in Zimbabwe, a development which saw the growing use of email in central government, especially owing to the e-government programme.

Personal observation by researchers in 10 out of the 22 government ministries where observation access was granted revealed that almost every office had online computers. The researchers also saw servers, email files and email paper printouts, which pointed to the use of email in the 10 ministries. Researchers also relied on documents in support of respondents' views that email had become a very popular ICT for sending and receiving information. In ministries D, I, L and N, researchers saw records survey reports produced by NAZ archivists. The reports confirmed that the four ministries used email, although there were challenges in professionally managing the same.

The second objective of the study was to establish the types of records generated and sent using mail in Zimbabwe's central government. The 240 questionnaire respondents indicated that the most common types of records normally sent and received through email were correspondence, minutes, memoranda, reports and policies. Table 3 succinctly shows their responses.

Table 3: Types of records normally sent and received through email

\begin{tabular}{|l|c|c|}
\hline Type of record & Frequency & Percentage \\
\hline Correspondences & 222 & 92.5 \\
\hline Minutes of meetings & 220 & 91.7 \\
\hline Memoranda & 210 & 87.5 \\
\hline Reports & 210 & 87.5 \\
\hline Policies & 198 & 82.5 \\
\hline Operations records & 160 & 66.7 \\
\hline Contracts & 147 & 61.3 \\
\hline Appointment letters & 106 & 44.2 \\
\hline Financial records & 102 & 42.5 \\
\hline Instructions & 89 & 37.1 \\
\hline Requisitions & 87 & 36.3 \\
\hline Assets registers & 82 & 34.2 \\
\hline Leave applications & 74 & 30.8 \\
\hline
\end{tabular}




\begin{tabular}{|l|c|c|}
\hline Type of record & Frequency & Percentage \\
\hline Tax returns & 50 & 20.8 \\
\hline Staff appraisals & 49 & 20.4 \\
\hline Investment projects & 42 & 17.5 \\
\hline Other & 32 & 13.3 \\
\hline
\end{tabular}

The majority of NAZ archivists (6: 86\%), through interviews, corroborated the fact that the most common types of records communicated through email were minutes, correspondence, reports and memoranda. They further indicated that these were the most common types of records communicated through email because these records were the most common administrative records found in government.

Through questionnaires, the study also revealed that finance and human resources records were the least communicated through email. Examples of these were investment projects, tax returns, staff appraisals and leave applications. NAZ3 indicated that finance and human resources records, for example, tax returns and investment projects, were least communicated through email because they were records of a sensitive nature and, as such, they are mostly communicated through other channels other than email. In trying to further establish the prevalence of the use of email in Zimbabwe's central government, the third and last objective of the study probed the average volume of email sent and received by government ministries in a single day. Researchers asked respondents to indicate the average number of emails they received in a single day. The following results as shown in Table 4 were obtained.

Table 4: Emails received by ROs, AOs and ITOs per day ( $N=\mathbf{2 4 0})$

\begin{tabular}{|l|l|l|l|l|l|l|l|}
\hline $\begin{array}{l}\text { Email } \\
\text { volume }\end{array}$ & $\mathbf{0 - 9}$ & $\mathbf{1 0}-\mathbf{1 9}$ & $\mathbf{2 0}-\mathbf{2 9}$ & $\mathbf{3 0}-\mathbf{3 9}$ & $\mathbf{4 0}-\mathbf{4 9}$ & $\mathbf{5 0}-\mathbf{5 9}$ & Totals \\
\hline ROs & $5(2.08 \%)$ & $15(6.25 \%)$ & $30(12.5 \%)$ & $20(8.33 \%)$ & $7(2.92 \%)$ & $3(1.25 \%)$ & $\mathbf{8 0}(\mathbf{3 3 . 3 3})$ \\
\hline AOs & $3(1.25 \%)$ & $13(5.42 \%)$ & $35(14.58 \%)$ & $17(7.08 \%)$ & $7(2.92 \%)$ & $5(2.08 \%)$ & $\mathbf{8 0}(\mathbf{3 3 . 3 3})$ \\
\hline ITOs & $31(12.92 \%)$ & $22(9.16 \%)$ & $16(6.67 \%)$ & $10(4.17 \%)$ & $1(0.41 \%)$ & $0(0 \%)$ & $\mathbf{8 0}(\mathbf{3 3 . 3 3})$ \\
\hline Totals & $\mathbf{3 9}(\mathbf{1 6 . 2 5 \% )}$ & $\mathbf{5 0}(\mathbf{2 0 . 8 3} \%)$ & $\mathbf{8 1}(\mathbf{3 3 . 7 5 \%})$ & $\mathbf{4 7}(\mathbf{1 9 . 5 8} \%)$ & $\mathbf{1 5}(\mathbf{6 . 2 5 \% )}$ & $\mathbf{8 ( 3 . 3 3 \% )}$ & $\mathbf{2 4 0}(\mathbf{1 0 0})$ \\
\hline
\end{tabular}

The results of the survey indicated that $39(16.25 \%)$ respondents received between zero and nine emails per day; 50 (20.83\%) received between 10 and 19 emails per day; $81(33.75 \%)$ received between 20 and 29 emails per day; 47 (19.58\%) received between 30 and 39 emails per day; $15(6.25 \%)$ received between 40 and 49 emails; and eight $(3.33 \%)$ received between 50 and 59 emails per day. The most common category, the mode, was the 20 to 29 emails category, which had 81 respondents. The IT director (D3) in one government ministry explained that many officers spent much time during their day reading, sending or responding to email. He further revealed that many officers were so engrossed in email that it was affecting other organisational activities.

The study computed the mean of grouped data in order to establish the average volume of emails that each officer in central government received per day. The study applied the formula for computing mean of grouped data where one establishes the midpoint $(\mathrm{x})$ of the class interval, multiply it by the frequency for each category and divide the result by the number of observations. Table 5 shows the computation of the mean of grouped data with regard to emails received per day. 
Table 5: Computation of the average volume of emails received by ROs, AOs and ITOs per day

\begin{tabular}{|c|c|c|c|}
\hline Class interval & Frequency (f) & Midpoint (x) & Fx \\
\hline $0-9$ & 39 & 19.5 & 760.5 \\
\hline $10-19$ & 50 & 25 & 1250 \\
\hline $20-29$ & 81 & 40.5 & 3280.5 \\
\hline $30-39$ & 47 & 23.5 & 1104.5 \\
\hline $40-49$ & 15 & 7.5 & 112.5 \\
\hline $50-59$ & 8 & 4 & 32 \\
\hline Totals & $\mathbf{n}=\mathbf{2 4 0}$ & - & $\sum \mathrm{fx}=\mathbf{6 5 4 0}$ \\
\hline
\end{tabular}

Formula for mean of grouped data

$$
\begin{aligned}
& =\frac{\sum \mathrm{fx}}{\mathrm{n}} \\
& =\frac{6540}{240} \\
& =27.25 \\
& =27 \text { emails per day }
\end{aligned}
$$

On average, each RO, AO and ITO received 27 official emails per day. Such a volume was rather too much for officers who had other duties to perform besides attending to email.

The study also established the volume of email sent by each officer in central government in a day. Table 6 shows the volume of email that ROs, AOs and ITOs sent per day.

Table 6: Emails sent by ROs, AOs and ITOs per day ( $\mathrm{N}=\mathbf{2 4 0})$

\begin{tabular}{|l|l|l|l|l|l|l|l|}
\hline $\begin{array}{l}\text { Email } \\
\text { volume }\end{array}$ & $\mathbf{0 - 9}$ & $\mathbf{1 0}-\mathbf{1 9}$ & $\mathbf{2 0}-\mathbf{2 9}$ & $\mathbf{3 0}-\mathbf{3 9}$ & $\mathbf{4 0}-\mathbf{4 9}$ & $\mathbf{5 0}-\mathbf{5 9}$ & Total \\
\hline ROs & $5(2.08 \%)$ & $15(6.25 \%)$ & $30(12.5 \%)$ & $20(8.33 \%)$ & $8(3.33 \%)$ & $2(0.83 \%)$ & $80(33.33 \%)$ \\
\hline AOs & $3(1.25 \%)$ & $12(5 \%)$ & $35(14.58 \%)$ & $17(7.08 \%)$ & $8(3.33 \%)$ & $5(6.25 \%)$ & $80(33.33 \%)$ \\
\hline ITOs & $39(16.25 \%)$ & $22(9.17 \%)$ & $15(6.25 \%)$ & $4(1.67 \%)$ & $0(0 \%)$ & $0(0 \%)$ & $80(33.33 \%)$ \\
\hline Total & $\mathbf{4 7 ( 1 9 . 5 8 \% )}$ & $\mathbf{4 9}(\mathbf{2 0 . 4 2 \%})$ & $\mathbf{8 0}(\mathbf{3 3 . 3 3 \%})$ & $\mathbf{4 1}(\mathbf{1 7 . 0 8} \%)$ & $\mathbf{1 6}(\mathbf{6 . 6 7 \%})$ & $\mathbf{7}(\mathbf{2 . 9 1 \%})$ & $\mathbf{2 4 0}(\mathbf{1 0 0} \%)$ \\
\hline
\end{tabular}

Most (80: 33.3\%) respondents revealed that they sent between 20 and 29 emails per day. The lowest range of email volume sent was 50 to 59 emails. Most (39: 48.75\%) ITOs sent between zero and nine emails per day, while most ROs (30: 37.5\%) sent between 20 and 29 emails per day and most (35: 43.75\%) AOs sent between 20 and 29 emails per day. The modal class was the 20 to 29 emails with 80 respondents. The average number of emails sent in a day by each officer is shown Table 7. 
Table 7: Computation of the average volume of email sent by ROs, AOs and ITOs per day

\begin{tabular}{|c|c|c|c|}
\hline Class interval & Frequency (f) & Midpoint (x) & Fx \\
\hline $0-9$ & 47 & 23.5 & 1104.5 \\
\hline $10-19$ & 49 & 24.5 & 1200.5 \\
\hline $20-29$ & 80 & 40 & 3200 \\
\hline $30-39$ & 41 & 20.5 & 840.5 \\
\hline $40-49$ & 16 & 8 & 128 \\
\hline $50-59$ & 7 & 3.5 & 24.5 \\
\hline Totals & $\mathbf{n = 2 4 0}$ & - & $\sum \mathrm{fx}=\mathbf{6 4 9 8}$ \\
\hline
\end{tabular}

Mean for grouped data

$$
\begin{aligned}
& =\frac{\sum f \mathrm{x}}{\mathrm{N}} \\
& =\frac{6498}{240} \\
& =27.075 \\
& =\underline{\mathbf{2 7} \text { emails sent per day }}
\end{aligned}
$$

On average, each RO, AO and ITO sent 27 emails per day. This shows that dealing with email was quite taxing given that the same officer was set to receive another 27 official emails during the same day. This was in addition to the daily non-email routine work that the officers were expected to undertake.

Interviewees who generally indicated that email had become a major preoccupation in Zimbabwe's central government concurred with the study findings. Most (6: 86\%) NAZ archivists expressed that the use of email in official business had grown so much in central government that it affected other daily activities. In support of archivists was D2, the administration director from central government, who indicated that administrative work relies heavily on email, a situation which resulted in officers in central government spending part of their working day dealing with email. Sending and receiving on average 54 emails ( 27 received +27 sent) meant that the use of email had risen to unprecedented levels in central government, thus rather making it an emergent ICT culture, where the public sector was generally "emailising".

\section{Discussion of findings}

The first objective of this study was to establish whether or not email was the most frequently used ICT for sending and receiving information in Zimbabwe's central government. A total of $177(74 \%)$ respondents, five (71\%) NAZ archivists and D2 (an administration director in central government) concurred that email had become the most common ICT for sending and receiving information. Such a situation was also found in subsidiary bodies in Zimbabwe where Sigauke et al. (2016:14) revealed that there was a high usage of email in state universities, where as much as $50 \%$ of records were generated or communicated through email. Outside Zimbabwe, an almost similar situation was found in Botswana where Rakemane and Serema (2018:156) state that the frequency of using email relative to other electronic records was 38.6\%. Overseas, Pignata, Lushington, Sloan and Buchanan (2015:159) revealed that in countries like Britain and Australia, email had drastically changed the nature of communication 
and had supplanted other modes of communication like telephones and telegrams. Thus, the situation prevailing in Zimbabwe was also seen in many other countries, confirming the dominant position of email in sending and receiving information in official business.

The second objective of this study was to identify the types of records normally sent and received through email in Zimbabwe's central government. The study revealed that almost all types of records within central government were communicated through email. Examples of these were minutes of meetings, memoranda, correspondences, reports and policies. It was also revealed that sensitive and classified records were least communicated through email. Studies such as those done by Mutsagondo (2017:23) on electronic records management in Zimbabwe and Sibanda (2017:27) on the preservation of records in Zimbabwe revealed that the most common types of electronic records in government ministries were administrative records, namely correspondences, reports, memoranda, policies, minutes of meetings and circulars. As a result, these were the same records that were mostly sent and received through email within Zimbabwe's central government. The dominant position of email in the public sector has also been seen by Prexawanprasut and Chaipornkaew (2017:783) who indicate that in many cases, employees and their clients mostly communicate through email and that whenever employees need to communicate, their first preference is to use email.

While minutes, correspondence, memoranda and policies were mostly communicated through email, records of a sensitive nature were least communicated through email. Scholars like Choudhary and Ghusinga (2013:42) attribute this to the issue of privacy and security. They argue that records with high security risk indices were less communicated through email than those with low risk indices. Mammo (2012:6) opines that electronic records are generally more prone to security risks than records in paper format due to the fact that they are more liable to unauthorised access, and unauthorised modification and alteration. This makes it important for organisations to categorise records to communicate on email and on other platforms as the privacy and security assessment dictate.

The third and last objective of this study was to establish the average volume of email that officers in central government sent and received in a single working day. It was seen that on average, each RO, AO and ITO received 27 official emails per day and sent 27 official emails per day. The fact that on average, each respondent handled 54 emails ( 27 received +27 sent) per day means officers in Zimbabwe's central government were generally engrossed in working with email in a single day. This must be taxing given that officers in central government have other official non-email duties to perform. The fact that email has become part and parcel of officers' daily routine is supported by Phrasee (2020:1) who states that, on average, one officer received 96 emails per day and sent 30 emails per day in 2019, in a world with over 2.6 billion active email users who have 4.6 billion email accounts. Another scholar, MacKay (2019:1), estimates that 132 million business emails were sent per day in the world in 2017. One can safely say that the Zimbabwean scenario of relying on email for sending and receiving information was in sync with international trends.

\section{Conclusion and recommendations}

There is widespread use of email in Zimbabwe's public sector, including the central government. This has been attributed to the adoption of e-government and to the inherent 
advantages of email as shown by the innovation diffusion theory. Many public records are being sent and received via email and among these are minutes of meetings, correspondence, memoranda, reports and policies. The study revealed that, on average, a single government officer received 27 emails and sent 27 emails per day. This was rather a large volume of work to contend with given that these officers had other duties to perform besides receiving, reading and responding to emails. Thus, one can comment that "emailisation" of Zimbabwe's public sector, including central government, is a reality which has taken the ICT front by storm. This calls for attention and paradigm shift in the manner in which Zimbabwe's central government approaches and uses email, making it necessary for the study to prescribe some recommendations.

There is need for central government to heavily invest in email technology, for example, the electronic documents and records management system, which is currently used in the world to professionally manage email records. Zimbabwe's central government currently does not have such technology, implying that the management of email as official records is currently in disarray. There is also a need for training in email records management for all officers in central government since all officers receive and send official email in the course of conducting official business. In addition to records officers, information technology officers and administration officers, training should be extended to human resource officers, procurement officers, operations officers and lower level staff, among others. Lastly, email policies need to be crafted and applied across government so that email can be used in a professional and official manner in line with the ethos of the NAZ Act (1986) as well as international records management best standards. The current "do as you like" approach to using and managing email is unsustainable and needs to be checked and corrected. "Emailisation" should be officially supported for it to be meaningful, relevant and beneficial to Zimbabwe's public sector, including central government.

\section{Implications of the study on both theory and practice}

This study has implications for theory and practice as derived from the innovation diffusion theory. As innovation diffuses, there is a need to observe integrity and professionalism so that society may adopt, apply and practically use relevant and compatible aspects of the innovation. The more technology is used, the more attention society should pay to it in terms of human resources, skills, infrastructure, legal, policy, and procedural frameworks. The study may greatly contribute to the crafting of an email usage policy in the public sector which hitherto does not exist in Zimbabwe.

\section{References}

Bhebhe, S. 2015. Contemporary diplomatics of the civil and deceased estate case files found at the National Archives of Zimbabwe. Records Management Journal 25(1): 107-120.

Chihambakwe, S., Wutete, O. \& Sigauke, D.T. 2017. Fostering corporate memory through the management of email records: the case of a commercial banking institute in Zimbabwe. Paper presented at the University of Botswana Department of Library and Information Science, 7 - 10 October 2017, Gaborone, Botswana.

Choudhary, S. \& Ghusinga, R. 2013. Email security: issues and solutions. International Journal of Computer Information Systems 7(4): 42-63. 
Cloy, D. 2007. Managing email: good practice guidance. Stirling: University of Stirling.

Dearing, J.W. \& Cox, J.G. 2018. Diffusion of innovation theory, principles and practice. Health affairs 37(2): 183-190.

Desai, M.S., Hart, J. \& Richards, T.C. 2015. An IT manager's view on e-mail and Internet policies and procedures. Journal of Instructional Psychology 36(4): 319-322.

Dibra, M. 2015. Rogers theory on diffusion of innovations: the most appropriate theoretical model in the study factors influencing the integration of sustainability in tourism business. Procedia: Social and Behavioural Sciences 195: 1453-1462.

Kupritz, V.W. \& Cowell, E. 2011. Productive management communication: online and face to face. Journal of Business Communication 48(1): 54-82.

Mackay, J. 2019. Does your email inbox make you sweat? Here's how to get a handle on email overload. Rescue Time: 1-14.

Mammo, W. 2012. Assessment of application of electronic records management systems in Ethiopia using Technology Acceptance Model. Paper presented at the SCECSAL 20th Conference at the Laico Regency Hotel, 4- 8 June 2012, Nairobi, Kenya.

Matangira, V. 2016. Records and archives management in post-colonial Zimbabwe's Public Service. DPhil thesis, University of Namibia, Windhoek.

Middaugh, D. 2015. The voice of e-mail. Nursing Management 24(4): 277-278. July-August.

Mutsagondo, S. 2017. Electronic records management in the Midlands province of Zimbabwe. MInf dissertation, University of South Africa, Pretoria.

Ngulube, P. 2018. Overcoming difficulties associated with using conceptual and theoretical frameworks in heritage studies. In Ngulube, P. (ed.). Handbook of research on heritage management and preservation. Hersheley: IGI Global: 1-25.

Ngulube, P. 2020. The movement of mixed methods research and the role of information science professionals. In Ngulube, P. (ed.). Handbook of research on connecting research methods for information science research. Hersheley: IGI Global, 425-455.

Phrasee. 2020. A brief history of email: dedicated to Ray Tomlinson. np.

Pignata, S., Lushington, K., Sloan, J. \& Buchanan F. 2015. Employees' perceptions of email communication, volume and management strategies in an Australian university. Journal of Higher Education Policy and Management 37(2): 159-171.

Prexawanprasut, T. \& Chaipornkaew, P. 2017. Email classification model for workflow management systems. Walailak Journal 14(10): 783-790.

Rakemane, D. \& Serema, B.C. 2018. ERM practices at the Companies and Intellectual Property Authority in Gaborone, Botswana. Journal of South African Society of Archivists 51: 148-169.

Sejane, L. 2004. An investigation into the management of electronic records in the public sector in Lesotho. MIS Thesis, University of KwaZulu-Natal, Pietermaritzburg.

Sibanda M. 2017. Preventive conservation challenges of public sector records in the Mashonaland West Province of Zimbabwe. MInf dissertation, University of South Africa, Pretoria.

Sigauke, D.T., Nengomasha, C.T. \& Chabikwa, S. 2016. Management of email as electronic records in state universities in Zimbabwe: findings and implications for the National Archives of Zimbabwe. ESARBICA Journal 34: 14-29.

Scott, S. \& McGuire, J. 2017. Using diffusion of innovations theory to promote universally designed college instruction. International Journal of Teaching and Learning in Higher Education 29(1): 119-128. 
Samson Mutsagondo \& Patrick Ngulube

The Radicarti Group. 2019. Email statistics report. www.fliphtml5.com/utch/wtn (accessed 3 June 2019).

Zimbabwe. 1986. National Archives of Zimbabwe Act. Harare: Government Printer. 